\title{
The Importance of Fluoride Dentifrices to the Current Dental Caries Prevalence in Brazil
}

\author{
Jaime Aparecido CURY \\ Livia Maria Andaló TENUTA \\ Cecilia Claudia Costa RIBEIRO \\ Adriana Franco PAES LEME \\ Faculty of Dentistry of Piracicaba, UNICAMP, Piracicaba, SP, Brazil
}

\begin{abstract}
Similar to that which occurred in most developed countries, dental caries have shown a significant decline in Brazil over the last two decades. Water fluoridation, expansion of preventive programs at schools, and especially, the widespread use of fluoride dentifrice are discussed as factors related to this reduction in caries. Data from epidemiological surveys and historical facts are presented to support the importance of fluoride dentifrices to the current caries prevalence in Brazil.
\end{abstract}

Key Words: dental caries, dentifrice, fluoride, water fluoridation.

\section{INTRODUCTION}

Caries decline has been observed in many countries since the 1970s and has been the subject of many discussions (1-10). Brazil, similar to other developing countries (11), has also shown a marked reduction in dental caries in the last decades (12-15).

Nevertheless, methods of caries prevention vary widely among countries where caries reduction was observed. Experts worldwide have cited several factors to explain this reduction, i.e., changes in diet, hygiene procedures, clinical management of caries and the widespread use of fluoride (2). Also, changes in the diagnostic criteria as to what constitutes a carious lesion should be considered (16). Although water fluoridation and preventive programs based on fluoride applications are considered very important to the decline, use of fluoride dentifrices has been pointed out as the only factor common to the different countries experiencing caries reduction, and their widespread use coincides with the timing of caries decline $(3,4)$. Their efficacy in preventing dental caries is clearly demonstrated in the literature (17). Caries also declined in communities in which no other important preventive method was available, except for fluoride dentifrices $(5,6)$, whereas countries where fluoride toothpastes are not widely used did not experience the same decrease in dental caries as observed in countries using these products (7).

In Brazil, no controlled study was ever conducted to evaluate the factors involved in caries decline. However, epidemiological studies conducted concomitantly with this decline may give some information on the reasons for it. Fluoridated water has been available since the 1960s and fluoride dentifrices reached the market on a large-scale basis in 1989. Fluoride is also used in preventive programs at schools. The relationship of these factors with the observed caries decline in Brazil has not yet been discussed in the literature. Thus, this review discusses the role of water fluoridation, preventive programs and especially of fluoride dentifrices on caries reduction in Brazil, based on available epidemiological data and historical facts.

\section{CARIES DECLINE IN BRAZIL}

Considering the size of the country, only a few epidemiological surveys have aimed at assessing the caries prevalence in all regions, including a recently finished national survey (Figure 1). These national surveys, conducted from 1968 to 2003, showed a sig-

Correspondence: Prof. Dr. Jaime A. Cury, Faculdade de Odontologia de Piracicaba, UNICAMP, Av. Limeira 901, 13414-903 Piracicaba, SP, Brasil. Tel: +55-19-3412-5303/5393. Fax: +55-19-3412-5218. e-mail: jcury@fop.unicamp.br 


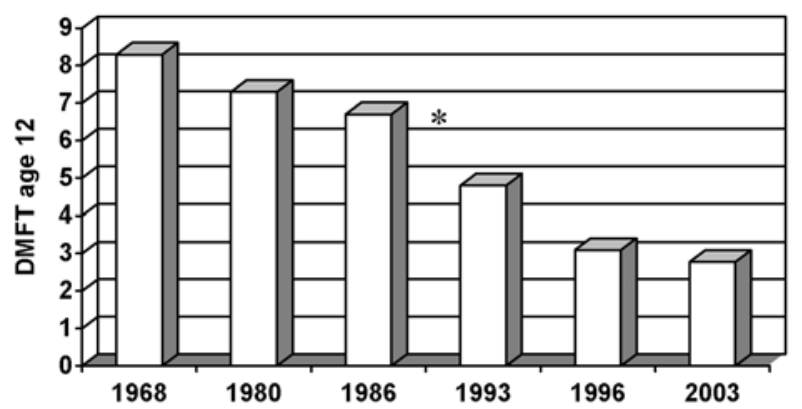

Figure 1. Caries decline in Brazil from 1968 to 2003. From Narvai, 2000 (14) and Health Ministry of Brazil (15) *1989: fluoride dentifrices reached the market on a large-scale basis.

nificant decrease in caries prevalence in Brazil in the last decades $(12,13,15)$. In 1968, according to WHO classification levels, Brazil presented a very high caries prevalence (8.3 DMFT at 12 years). This scenario changed to a moderate caries prevalence (2.8 DMFT) in 2003, according to the latest survey (15). Although the national surveys clearly demonstrate the decrease in dental caries in Brazil, they are subject to critics, mainly because of the methodology used. For example, the surveys of 1986 and $1996(12,13)$ included only the capitals of the states, and may not reflect the caries incidence in small cities, with lower overall development. Thus, when trying to investigate the reasons for the caries decline, one must also count on local and regional epidemiological surveys in order to give support to the arguments.

As seen worldwide, the reduction in mean caries prevalence in Brazilian children is accompanied by a polarization of the disease, with $50 \%$ of individuals accounting for almost $90 \%$ of caries prevalence (18). In $1986,19.5 \%$ of 12 -year-olds presented a DMFT of 3.0 or less, $45.3 \%$ presented a DMFT between 4.0 and 7.0 , and $35.2 \%$ presented more than 8.0 . In 2003, these numbers changed to $66.5 \%$ with less than 3.0 DMFT, $25.5 \%$ with a DMFT between 4.0 and 7.0 , and $8 \%$ with more than $8.0(15,18)$. This means that the reduction in the development and progression of the disease reached a large part of the population, but individuals with extreme risk factors were not benefited.

Studies have shown that different socioeconomic populations in Brazil present different caries experience $(19,20)$. Many of these studies separate children of different socioeconomic backgrounds according to their schools (19-21). Private schools (high tuition fees) are attended by high-income children, and public schools (no tuition) are attended by low-income children. An epidemiological survey conducted in 2002 in the state of São Paulo (21) showed a DMFT for 12-year-olds of 2.20 in private schools and 2.54 in public schools. Children free of caries at 12 years were $43 \%$ in private and $31 \%$ in public schools. Also, the components of the DMFT index are different between these two populations: there is an increase in the proportion of filled teeth over carious teeth for high-income when compared to low-income children, demonstrating a better access of high-income children to dental services (20).

In spite of the differences in caries prevalence for the different socioeconomic populations, both of them experienced a significant caries decline. This demonstrates that the factors influencing the decline reached the Brazilian population on a wide basis. Considering the size of Brazil and the few preventive measures that reached the entire country, only three main reasons were identified as very important to explain the caries decline: a) fluoridation of water; b) widespread use of fluoride dentifrices; c) expansion of preventive programs at schools $(14,22,23)$. Indeed, it was demonstrated (23) that São Paulo, the largest city in the country, did not show any decrease in caries prevalence from 1970 to 1983, when none of these three measures was available. A $68 \%$ reduction in caries prevalence between 1986 and 1996 in the city coincides with the initiation of water fluoridation in 1985, the availability of fluoride dentifrices on a largescale basis since 1989 and the spread of preventive programs from 1990. The role of these three factors will be discussed in detail later.

Other factors of minor importance to the caries decline must also be described. Significant improvements in life quality occurred in Brazil over the last decades. Since the 1960's, the percentage of households with piped water and electrical supply increased from $21 \%$ to $90 \%$ and from $39 \%$ to $93 \%$, respectively (24). This improvement certainly influenced the health of the population, including oral health. However, socioeconomic inequalities are still strong (i.e. the difference in earnings between the poorest and the richest families currently reaches 47 times (24)), and the access of low-income population to educational and preventive health services is not as effective as in developed countries. Free public dental services, except for those directed to children at schools, are limited to 
curative treatment, including restorations and extractions.

Considering the diet of Brazilians, it is not probable that any change in the consumption of sugar occurred during the last decades. Families from a low socioeconomic background have diets based mainly on carbohydrates, which are cheap and act as a sufficient source of energy.

The increasing emphasis on health promotion and caries prevention after the 1950s, that Krasse (8) considers important to the caries decline seen in new generations of Swedish children, may also have influenced caries in Brazil. Preventive medicine and dentistry has grown significantly over the years. In 1981, the Brazilian Association for Preventive Dentistry (ABOPREV) was founded in Jundiaí, SP, with the aim of changing the model of caries management in the country from a curative to a preventive one. The participation of ABOPREV reached national levels in 1989 and this Association worked as a consultant of the Brazilian government in the decisions about preventive measures and politics of health, culminating with the promotion of the 5th World Congress on Preventive Dentistry (WCPD) in Brazil in 1995. However, there is no controlled research to study the relationship between the interest in preventive dentistry and caries decline in the country.

Despite the possible role of the preventive philosophy of ABOPREV on caries reduction, the change in the paradigm of caries is positively related to the changes in diagnostic criteria for caries. Marcenes et al. (16) showed that the diagnostic criteria for caries 30 years ago, which included early stages of the disease, may be related to an inflation of the prevalence of caries at that time. Thus, caries reduction would not have been that sharp. However, irrespective of this change in epidemiological surveys, the authors demonstrate that a significant reduction in caries in fact occurred (16).

\section{ROLE OF WATER FLUORIDATION}

Water fluoridation was introduced in Brazil in 1953, and a federal law from 1975 advised water fluoridation in all cities having water treatment systems (25). However, even today there are regions that have not received fluoridated water, and it can be estimated that only $43 \%$ of the Brazilian population have this benefit (14). Most of the non-fluoridated cities are located in the northern region of the country, where social inequalities are higher and caries prevalence is greater.

The optimum fluoride level recommended for Brazil, $0.7 \mathrm{ppm}$, is checked by each city that has fluoridated water. This is an important control in order to assure adequate fluoride levels. As an example, Santos, a city in the state of São Paulo, underwent a rigorous control of water fluoridation: in 1990 , only $61 \%$ of samples of water collected had fluoride levels from 0.6 to $0.8 \mathrm{ppm}$, when the Health Secretary started a serious control of fluoridation. In 1993-94, this percentage had changed to 96 to $100 \%$ (26). Unfortunately, in some cities the control of fluoridation is not followed appropriately, and usually fluoride levels are below those recommended (27), depriving the population of its benefits.

The role of water fluoridation on caries reduction in Brazil is certain and has been demonstrated by many surveys. A $50 \%$ reduction in dental caries, as observed in other countries, was shown some years after the implementation of fluoridated water in many Brazilian cities $(14,28)$. This percentage of reduction was common before the availability of fluoride dentifrices in the country on a wide basis.

Currently, the extent of the contribution of water fluoridation to caries prevention has been questioned worldwide, mainly due to the confounding effect of the introduction of fluoride dentifrices. Data in the literature show that the difference in caries prevalence between fluoridated and non-fluoridated communities has decreased (1), and even after discontinuation of water fluoridation in some cities or countries, caries continued to decrease $(4,29)$. In Brazil, the same trend can be observed. The two national surveys conducted in capitals of states in 1986 and $1996(12,13)$ showed that significant reductions occurred in caries prevalence, irrespective of fluoridation of water (Table 1). The north and northeast regions of the country presented about $50 \%$ reduction in dental caries in 10 years, even though the cities studied did not present fluoridated water.

The decrease in the difference of caries experience between fluoridated and non-fluoridated cities is well demonstrated by Pereira et al. (30) (Figure 2). This Figure shows that the difference in dental caries prevalence between school children from two near cities, with and without water fluoridation, which was $50 \%$ in 
1991 , was reduced to approximately $20 \%$ in the following years. Recently, it was shown that the DMFT at 12 years in Brazil is 2.3 for fluoridated and 3.4 for nonfluoridated cities, a difference of about $30 \%$ (15).

These results demonstrate that, for the non-fluoridated cities, other factors are responsible for the caries decline. Although the effect of water fluoridation on the prevention of dental caries may have decreased with the introduction of other sources of fluoride, it is still regarded as an important preventive measure in Brazil $(31,32)$, especially for low-income people $(14)$, who may not benefit from adequate oral hygiene procedures. However, each community should assess the real cost-effectiveness of water fluoridation for its population.

\section{ROLE OF PREVENTIVE PROGRAMS}

Oral health services, with emphasis on oral health promotion, underwent a significant change in Brazil around 1990. Before this date, the government invested in "finished treatments", which meant that the child should have all cavities restored, and obviously encouraged restorative approaches. Since the beginning of the 1990 s, the health system changed in Brazil and municipalities gained more autonomy to spend federal resources with measures significant to their community. Dental health was influenced by this change, because the government started to support collective, preventive procedures. Each city would receive money according to the number of children participating in the

Table 1. Prevalence and reduction of dental caries in capitals of Brazilian states in 10 years.

\begin{tabular}{lcccc}
\hline Regions & $\begin{array}{c}\text { Water } \\
\text { fluoridation }\end{array}$ & 1986 & 1996 & Reduction (\%) \\
\hline North & absent & 7.50 & 3.52 & 53.1 \\
Northeast & absent & 6.90 & 3.13 & 54.6 \\
Centerwest & present in & 8.53 & 2.82 & 66.9 \\
& some capitals & & & \\
Southeast & present & 5.95 & 2.34 & 60.7 \\
South & present & 6.31 & 2.41 & 61.8 \\
Brazil & present in & 7.04 & 2.84 & 59.6 \\
& some capitals & & & \\
\hline
\end{tabular}

From the Health Ministry of Brazil, 1988 (12) and 1996 (13). preventive program. This promoted an expansion of preventive programs using fluoride at public schools. Such programs included supervision of toothbrushing at schools with fluoride dentifrice, weekly fluoride rinsing, APF application and dental treatment, according to the caries risk of children. The city was responsible for the toothbrush and fluoride dentifrice supplied to the student every 3 months. This permitted socioeconomic-deprived children to have access to fluoride dentifrices. However, due to regional differences occurring in a huge country like Brazil, these preventive measures were implemented more seriously in some cities than in others, and usually covered only a percentage of the public schools. Those cities with organized health systems that promptly adhered to the new approach experienced an early caries decline.

From 1975 to 1983, in Santos, a city in the state of São Paulo with a population of about 500,000, preventive measures included fluoride rinsing at schools and education on dental health to students and teachers, and in 1983, water was fluoridated. As a result of these measures, caries declined from DMFT 8.9 at 12 years in 1975 to 5.1 in 1989. Since 1990, preventive policies were followed closer, with free distribution of fluoride toothpastes and toothbrushes at schools, use of topical fluorides, treatment of children according to caries risk and control of fluoride levels in water. This resulted in a further decrease in caries prevalence, with $62.5 \%$ of children aged 5 free of caries and a DMFT for 12-yearolds of 1.7 in 1995 (26), quite less than the national mean (see Figure 1) (13). In Piracicaba, a city with a population similar to that of Santos and presenting fluoridated water, the preventive programs at schools started later, and only in 2002 did the city reach a

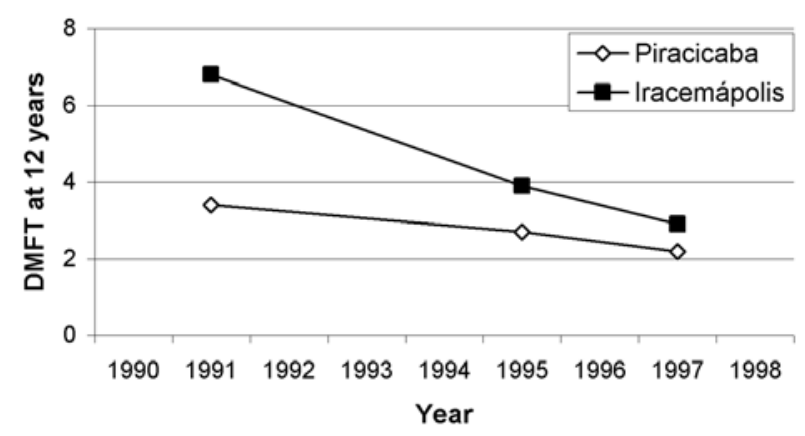

Figure 2. Caries reduction as a function of time in Piracicaba, SP (fluoridated water) and Iracemápolis, SP (non-fluoridated water). From Pereira et al. (30). 
DMFT for 12-year-olds of 1.96 (21).

Araraquara, another city in the state of São Paulo, also presented caries decline in preschool children 3 years after the implementation of a preventive program at preschools (33), which included education programs for parents, supervised toothbrushing at school, distribution of toothbrushes and fluoride dentifrices for the children every 3 months and weekly fluoride rinses.

Besides these 2 examples, the authors cannot ascertain the importance of collective preventive measures on caries decline in Brazil. School-based fluoride programs were related to the initial caries decline in Norway, when fluoride toothpastes were not yet available (9). However, the role of preventive programs in caries decline in developed countries is considered by some researchers to be of small importance $(2,29)$, and Nadanovsky and Sheiham (10) also showed that the contribution of dental services to caries decline in the 1970s was minimal. In Brazil, the preventive programs funded by the government benefit only public schools, with mainly low-income children. Even though a 90-g Brazilian fluoride dentifrice costs less than US $\$ 0.50$, the minimum salary today is around US $\$ 90$. Thus, these programs may be very important to allow the access of the low-income population to fluoride sources.

\section{ROLE OF FLUORIDE DENTIFRICES}

Exposure to fluoride dentifrices increased greatly in Brazil at the end of the 1980s. Before September 1988 , approximately $25 \%$ of dentifrices sold in Brazil contained fluoride, when the most popular Brazilian dentifrice was fluoridated (34). This fact increased the proportion of fluoride dentifrices on the market to $90 \%$ in 1990. Currently, 97\% of toothpastes sold in Brazil are fluoridated.

In 1981 , when $12 \%$ of dentifrices on the market were fluoridated, the consumption was of about $0.6 \mathrm{~g} /$ day per capita. At present, dentifrice consumption in Brazil is the third highest among countries reporting dentifrice consumption, with $1.4 \mathrm{~g}$ used per day per capita, only behind the United States and Japan (14).

According to a resolution in 1989 from the Ministry of Health (35), fluoride dentifrices should contain 1000 to $1500 \mu \mathrm{g} / \mathrm{g}(\mathrm{w} / \mathrm{w})$ of soluble fluoride either ionic or ionizable (monofluorphosphate, MFP) when manufactured, and after one year at least $600 \mu \mathrm{g} / \mathrm{g}$ of soluble fluoride had to be maintained. Unfortunately, this reso- lution was changed in 1994 (36), when the term "soluble" was removed, and until now, the rules (37) for fluoride dentifrice fabrication in Mercosur (common market among Argentina, Brazil, Paraguay and Uruguay) determine that they should contain a maximum of $0.15 \%$ of fluoride, irrespective of the salt of fluoride used, and its availability, and stability in the product.

Nevertheless, the quality of fluoride dentifrices in terms of availability and stability has improved over the years, as shown in Table 2. All dentifrices are made in the Southwest region and delivered to the rest of the country. The availability and stability of fluoride is maintained irrespective of the region where the dentifrice is purchased (38), showing that all populations benefit.

The four dentifrices that lead the sales (accounting for $80 \%$ of total) use calcium carbonate as abrasive, which is abundant in Brazil, and sodium monofluorophosphate as the source of fluoride, allowing a formulation with the potential to interfere with caries development. These calcium carbonate-based dentifrices, unique in Brazil, were tested in vitro (39) and in situ (40), and recently it was demonstrated that calcium carbonate might enhance the effect of fluoride present in the dentifrice (41), probably by its buffering properties and/or enhancement of calcium concentration in plaque (42). Irrespective of the abrasive used, Brazilian fluoride dentifrices have demonstrated ability to interfere with dental caries in in vitro $(39,43)$ and in situ $(40,44)$ studies. This gives support for a possible role of the Brazilian dentifrices on the caries decline that has been observed.

As already described, there is evidence that the availability of fluoride dentifrices on a large-scale basis to the Brazilian market is responsible for the reduction in caries prevalence between cities with and without fluoridated water (Table 1 and Figure 2). Only a method that reaches all heterogeneous population of the different regions of Brazil could be implicated in the caries decline observed all over the country in groups with different socioeconomic backgrounds.

On the other hand, there is no study evaluating the direct effect of fluoride dentifrices on caries decline in the country. National surveys should have been conducted when fluoride dentifrices were introduced, because an experimental design to evaluate fluoridated versus non-fluoridated toothpastes would be unethical today. Thus, evidence for the role of fluoride denti- 


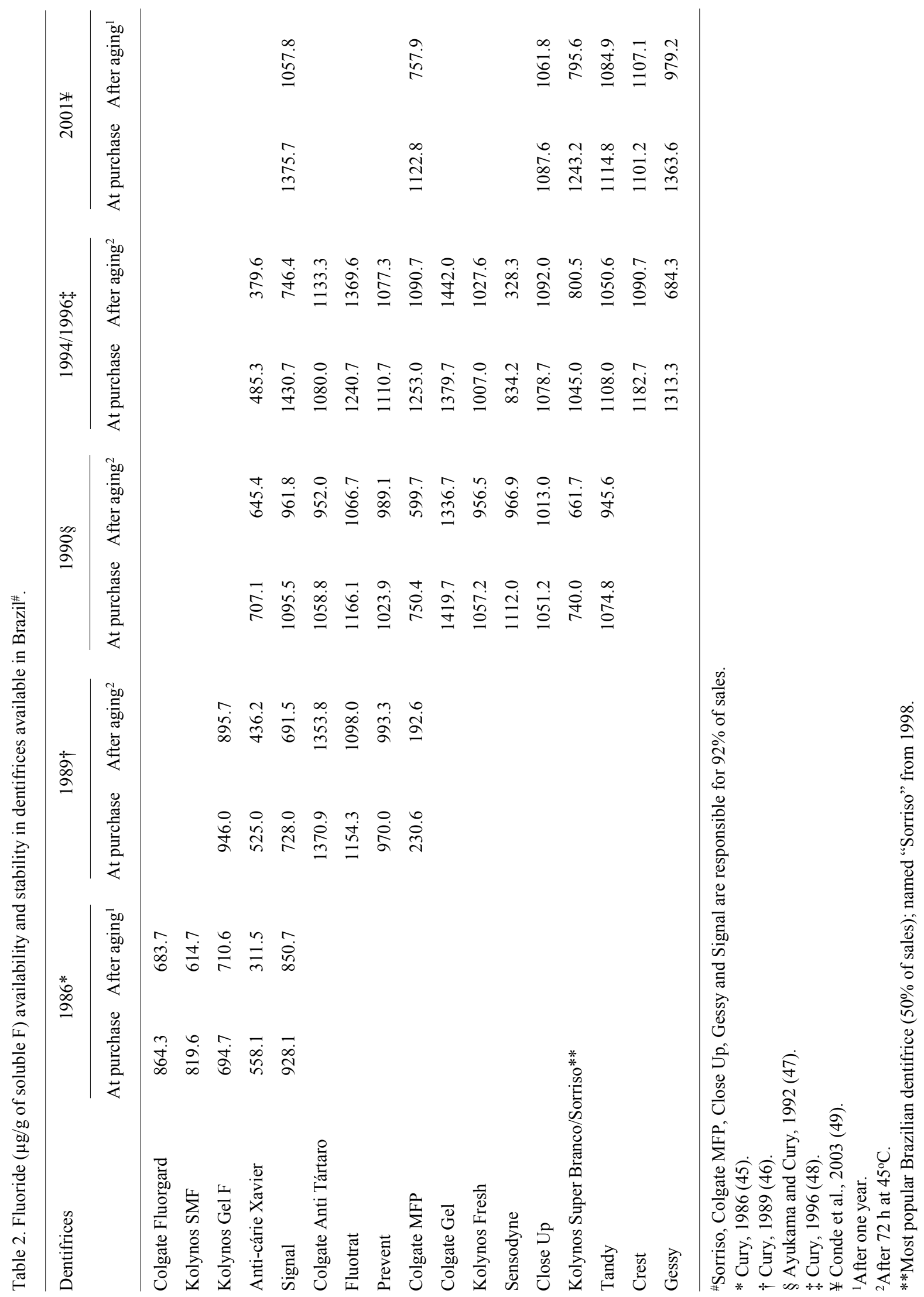


frices in caries decline relies on the concomitant availability of such products, in vitro and in situ studies of reduction of enamel demineralization or enhancement of remineralization, and a sharp reduction in caries prevalence.

\section{CONCLUDING REMARKS}

Data are presented to corroborate the hypothesis that water fluoridation, expansion of preventive programs at schools and the widespread use of fluoride dentifrices are consistently linked to the caries decline observed in Brazil in the last decades.

The role of water fluoridation in caries prevention has been shown worldwide, and this also seems to be the case for Brazil. Also, although some preventive programs have been proven efficient, it is difficult to ascertain their role in caries reduction until controlled research is made to evaluate the subject. Increased rates of caries reduction after fluoride dentifrices reached the market in 1989 and a minor difference in caries prevalence between regions with quite different preventive programs and exposure to fluoridated water give support to the major role of fluoride dentifrices in caries decline in Brazil.

Nevertheless, in a country of socioeconomic contrasts like Brazil, all preventive methods are of great importance to reach the greatest part of the population. Also, it must be noted that more research is needed to determine the efficacy of different methods for caries control, so that the government can spend resources where worthy.

\section{RESUMO}

Assim como observado na maioria dos países desenvolvidos, a prevalência de cárie dental no Brasil apresentou um declínio significativo nas últimas duas décadas. A fluoretação das águas de abastecimento público, a expansão de programas preventivos nas escolas e principalmente o uso abrangente de dentifrícios fluoretados no país são apresentados como fatores relacionados a essa redução de cárie. Dados de levantamentos epidemiológicos e fatos históricos são apresentados para corroborar a importância dos dentifrícios fluoretados na atual prevalência de cárie no Brasil.

\section{ACKNOWLEDGMENTS}

We would like to acknowledge Prof. Mônica Campos Serra, FORP-USP, who stimulated the writing of this article during the discipline "Experimental models on the clinical evaluation of dental materials" for the Graduate Program in Dentistry, Area of Cariology, Faculty of Dentistry of Piracicaba, UNICAMP.

\section{REFERENCES}

1. Brunelle JA, Carlos JP. Recent trends in dental caries in U.S. children and the effect of water fluoridation. J Dent Res 1990;69(Special Issue):723-727.

2. Bratthall D, Hänsel-Petersson G, Sundberg H. Reasons for the caries decline: what do the experts believe? Eur J Oral Sci 1996;104:416-422.

3. Rölla G, Ögaard B, Cruz RA. Clinical effect and mechanism of cariostatic action of fluoride-containing toothpastes: a review. Int Dent J 1991;41:171-174.

4. König KG. Role of fluoride toothpastes in a caries-preventive strategy. Caries Res 1993;27(Suppl 1):23-28.

5. Hargreaves JA, Cleaton-Jones PE. Dental caries changes in the Scottish isle of Lewis. Caries Res 1990;24:137-141.

6. Carvalho JC, Van Nieuwenhuysen JP, D'Hoore W. The decline in dental caries among Belgian children between 1993 and 1998. Comm Dent Oral Epidemiol 2001;29:55-61.

7. Bjarnason S. High caries levels: problems still to be tackled. Acta Odontol Scand 1998;56:176-178.

8. Krasse B. The caries decline: is the effect of fluoride toothpaste overrated? Eur J Oral Sci 1996;104:426-429.

9. Birkeland JM, Haugejorden O. Caries decline before fluoride toothpaste was available: earlier and greater decline in the rural north than in southwestern Norway. Acta Odontol Scand 2001;59:7-13.

10. Nadanovsky P, Sheiham A. relative contribution of dental services to the changes in caries levels of 12-year-old children in 18 industrialized countries in the 1970s and early 1980s. Comm Dent Oral Epidemiol 1995;23:331-339.

11. Fejerskov O, Baelum V, Luan W, Manji F. Caries prevalence in Africa and People's Republic of China. Int Den J 1994;44:425433.

12. Health Ministry of Brazil, National Secretary of Special Programs in Health, National Division of Oral Health. Epidemiological survey on oral health: Brazil, urban zone, 1986. Brasília, 1988 (in Portuguese).

13. Health Ministry of Brazil. DMFT in 12-year old Brazilian children. Braz Dental Ass News 1996;Nov-Dec (in Portuguese).

14. Narvai PC. Dental caries and fluoride: a relationship of the $20^{\text {th }}$ century. Ciência e Saúde Coletiva 2000;5:381-392 (in Portuguese).

15. Health Ministry of Brazil. SB Brazil 2003 Project - Oral health conditions of the Brazilian population 2002-2003. Brasília, DF, 2004 (in Portuguese). Available at $<\mathrm{http}: / /$ portal.saude.gov.br/ saude/arquivos/pdf/relatorio_brasil_sorridente.pdf $>$. Accessed November, 2004.

16. Marcenes W, Freysleben GR, Peres MAA. Contribution of changing diagnostic criteria toward reduction of caries between 1971 and 1997 in children attending the same school in Florianopolis, Brazil. Comm Dent Oral Epidemiol 2001:29;449-455.

17. Marinho VCC, Higgins JPT, Logan S, Sheiham A. Fluoride toothpastes for preventing dental caries in children and adolescents (Cochrane Review). The Cochrane Library, Issue 1, Oxford: Update Software, 2004.

18. Roncalli AG. Epidemiology of dental health in Brazil, 1986-1996 (in Portuguese). Available at $<\mathrm{http} / / /$ planeta.terra.com.br/saude/ angelonline/artigos/art_epid/epi_bra.pdf $>$. Accessed November, 2004. 
19. Freire MCM, Melo RB, Silva SA. Dental caries prevalence in relation to socioeconomic status of nursey school children in Goiânia-GO, Brazil. Comm Dent Oral Epidemiol 1996;24:357361.

20. Maltz M, Silva BB. Relationship between caries, gingivitis and fluorosis and the socioeconomic status among school children. Rev Saúde Pública 2001;35:170-176 (in Portuguese).

21. São Paulo State, Health Bureau. Oral health conditions in the state of São Paulo in 2002 - São Paulo State, 2002 (in Portuguese).

22. Narvai PC, Frazão P, Castellanos RA. Decline in dental caries experience in permanent teeth of the Brazilian schoolchildren at the end of $20^{\text {th }}$ century. Odontologia e Sociedade 1999;1:25-29 (in Portuguese).

23. Narvai PC, Castellanos RA, Frazão P. Dental caries prevalence in permanent teeth of schoolchildren in São Paulo, SP, Brazil, 19701996. Rev Saúde Pública 2000;34:196-200 (in Portuguese).

24. Instituto Brasileiro de Geografia e Estatística (Brazilian Institute of Geography and Statistics). Statistics of the 20th century (in Portuguese). Available at <http://www.ibge.gov.br $>$. Accessed November, 2004

25. Health Ministry of Brazil. Decree 635, December 26, 1975 (in Portuguese)

26. Manfredini MA. A technical report about oral health in Santos, SP, Brazil. Department of Hygiene and Health - Oral Health Technical Group 1996 (in Portuguese).

27. Maia LC, Valença AMG, Soares EL, Cury JA. Operational control of water fluoridation in Niterói, Rio de Janeiro, Brazil. Cad Saúde Pública 2003;19:61-67 (in Portuguese).

28. Basting RT, Pereira AC, Meneghim MC. Evaluation of dental caries prevalence in students from Piracicaba, SP, Brazil, after 25 years of fluoridation of the public water supply. Rev Odontol Univ São Paulo 1997;11:287-292 (in Portuguese).

29. Seppä L, Kärkkäinen S, Hausen H. Caries frequency in permanent teeth before and after discontinuation of water fluoridation in Kuopio, Finland. Comm Dent Oral Epidemiol 1998;26:256262.

30. Pereira AC, Mialhe FL, Bianchini FLC, Meneghim MC. Prevalence of caries and dental fluorosis in scholars from cities with different fluoride concentrations in drinking water. Rev Bras Odontol Saúde Coletiva 2001;2:34-39 (in Portuguese).

31. Lawrence HP, Sheiham A. Caries progression in 12- to 16-yearold schoolchildren in fluoridated and fluoride-deficient areas in Brazil. Comm Dent Oral Epidemiol 1997;25:402-411.

32. Sampaio FC, Hossain ANMN, von der Fehr FR, Arneberg P. Dental caries and sugar intake of children from rural areas with different water fluoride levels in Paraíba, Brazil. Comm Dent Oral Epidemiol 2000;28:307-313.

33. Dini EL, Foschini ALR, Mendonça FCC, Nardo G, Abbade MTG,
Frais RLMS. Prevalence of caries in preschool children after 3 years of a dental health program in Araraquara, SP. Rev Odontol USP 1996;10:55-59 (in Portuguese).

34. Cury JA. Fluoridated dentifrices in the Brazilian market and their potential as a preventive method. Special publication from the Brazilian Association for Preventive Dentistry, 1990:1-8 (in Portuguese).

35. Health Ministry of Brazil. Sanitary Vigilance Secretariat. Decree 22, December 20, 1989 (in Portuguese).

36. Health Ministry of Brazil. Sanitary Vigilance Secretariat. Decree 108, September 26, 1994 (in Portuguese).

37. Sanitary Vigilance Secretariat. Resolution 79, August 28, 2000 (in Portuguese).

38. Duarte FF, Pisaneschi E, Cury JA. Fluoride availability and stability in the popular fluoridated toothpastes sold in the five Brazilian regions. Rev ABOPREV 1999;2:3-10 (in Portuguese).

39. Delbem ACB, Vieira AEM, Cury JA. Evaluation of the cariostatic potential of the most popular Brazilian dentifrice. Rev Bras Odontol 2002;59:14-18 (in Portuguese).

40. Koo H, Cury JA. In situ evaluation of a dentifrice containing MFP/DCPD on fluoride uptake and remineralization by human dental enamel. Rev Odontol USP 1999;13:245-249 (in Portuguese).

41. Cury JA, Francisco SB, Simões GS, Del Bel Cury AA, Tabchoury CPM. Effect of a calcium carbonate-based dentifrice on enamel demineralization in situ. Caries Res 2003;37:194-199.

42. Cury JA, Simões GSN, Del Bel Cury AA, Gonçalves NC, Tabchoury CPM. Effect of a calcium carbonate-based dentifrice on in situ enamel remineralization. Caries Res 2005 (in press).

43. Paes Leme AF, Tabchoury CPM, Zero DT, Cury JA. Effect of fluoridated dentifrice and acidulated phosphate fluoride application on early artificial carious lesions. Am J Dent 2003;16:91-95.

44. Paes Leme AF, Dalcico R, Tabchoury CPM, Del Bel Cury AA, Rosalen PL, Cury JA. In situ effect of frequent sucrose exposure on enamel demineralization and on plaque composition after APF application and F-dentifrice use. J Dent Res 2004;83:71-75.

45. Cury JA. Stability of fluoride in Brazilian dentifrices. Rev Gaúcha Odontol 1986;34:430-432 (in Portuguese).

46. Cury JA. Fluoride dentifrices in Brazil. Rev Gaúcha Odontol 1989;37:139-142 (in Portuguese).

47. Ayukama SA, Cury JA. Fluoride dentifrices in Brazil. Cadernos Aboprev (Winners of the Colgate National Award on Preventive Dentistry) 1992:7-15 (in Portuguese).

48. Cury JA. Fluoride dentifrices in Brazil. J Aboprev 1996;7 (in Portuguese).

49. Conde NCO, Rebelo MAB, Cury JA. Evaluation of the fluoride stability of dentifrices sold in Manaus, AM, Brazil. Pesq Odontol Bras 2003;17:247-253. 